\title{
Development, characterization, and skin delivery studies of related ultradeformable vesicles: transfersomes, ethosomes, and transethosomes
}

This article was published in the following Dove Press journal:

International Journal of Nanomedicine

18 September 2015

Number of times this article has been viewed

\author{
Andreia Ascenso' \\ Sara Raposo' \\ Cátia Batista ${ }^{2}$ \\ Pedro Cardoso ${ }^{2}$ \\ Tiago Mendes ${ }^{2}$ \\ Fabíola Garcia Praça ${ }^{3}$ \\ Maria Vitória Lopes Badra \\ Bentley ${ }^{3}$ \\ Sandra Simões' \\ 'Instituto de Investigação do \\ Medicamento (iMed.ULisboa), \\ ${ }^{2}$ Faculdade de Farmácia, Universidade \\ de Lisboa, Lisboa, Portugal; ${ }^{3}$ Faculdade \\ de Ciências Farmacêuticas de \\ Ribeirão Preto, Universidade de São \\ Paulo, Monte Alegre, Ribeirão Preto, \\ São Paulo, Brazil
}

Correspondence: Andreia Ascenso Nanomedicine and Drug Delivery Systems Group, iMed, Faculty of Pharmacy of the University of Lisbon, Av Prof Gama Pinto, 1649-003 Lisbon, Portugal

Tel +35I 217946427

Fax +35I 217937703

Email andreiaascenso@ff.ul.pt
Abstract: Ultradeformable vesicles (UDV) have recently become a promising tool for the development of improved and innovative dermal and transdermal therapies. The aim of this work was to study three related UDV: transfersomes, ethosomes, and transethosomes for the incorporation of actives of distinct polarities, namely, vitamin $\mathrm{E}$ and caffeine, and to evaluate the effect of the carrier on skin permeation and penetration. These actives were incorporated in UDV formulations further characterized for vesicles imaging by transmission electron microscopy; mean vesicle size and polydispersity index by photon correlation spectroscopy; zeta potential by laser-Doppler anemometry; deformability by pressure-driven transport; and incorporation efficiency (IE) after actives quantification by high-performance liquid chromatography. Topical delivery studies were performed in order to compare UDV formulations regarding the release, skin permeation, and penetration profiles. All UDV formulations showed size values within the expected range, except transethosomes prepared by "transfersomal method", for which size was smaller than $100 \mathrm{~nm}$ in contrast to that obtained for vesicles prepared by "ethosomal method". Zeta potential was negative and higher for formulations containing sodium cholate. The IE was much higher for vitamin E- than caffeine-loaded UDV as expected. For flux measurements, the following order was obtained: transethosomes (TE) $>$ ethosomes $(\mathrm{E}) \geq$ transfersomes $(\mathrm{T})$. This result was consistent with the release and skin penetration profiles for Vitamin E-loaded UDV. However, the releasing results were totally the opposite for caffeine-loaded UDV, which might be explained by the solubility and thermodynamic activity of this active in each formulation instead of the UDV deformability attending to the higher non-incorporated fraction of caffeine. Anyway, a high skin penetration and permeation for all caffeine-loaded UDV were obtained. Transethosomes were more deformable than ethosomes and transfersomes due to the presence of both ethanol and surfactant in their composition. All these UDV were suitable for a deeper skin penetration, especially transethosomes.

Keywords: lipid vesicles, topical delivery studies, vitamin E, caffeine

\section{Introduction}

Several strategies have been used in order to overpass the stratum corneum (SC) barrier. Among other drug delivery systems, liposomes were used for topical drug delivery. ${ }^{1}$ Liposomes are typically hollow spheres surrounded by a lipid doubled layer. Once applied on skin surface, they only remain in the upper layer of the SC, acting as a drug reservoir. ${ }^{2}$ Thus, due to their unstable nature and poor skin permeability, they are only suitable for topical drug delivery. ${ }^{3}$

In order to overcome these limitations, novel lipid vesicles known as deformable or elastic (flexible) liposomes - ultradeformable vesicles (UDV) - were developed in the beginning of the 1990s. ${ }^{1}$ As UDV are more deformable than conventional liposomes, 
they have demonstrated a great ability to cross the intact skin and deliver the loaded drugs into the epidermis and dermis layers or even to the systemic circulation. Phospholipids, ethanol, bile salts, and many surfactants have been used for the preparation of these elastic vesicles. ${ }^{4}$

UDV present the advantages of being nontoxic and thermodynamically stable formulations. ${ }^{5}$ They have been used for dermal and transdermal delivery of many molecules including peptides and proteins. ${ }^{6}$ In addition, their production is relatively simple and easy to scale up.

Currently, there are many types of UDV that have been successfully developed for both pharmaceuticals and cosmeceuticals, particularly transfersomes, ethosomes, and, more recently, transethosomes (Figure 1). ${ }^{7}$

Transfersomes are elastic nanovesicles essentially made of phospholipids and edge activators (EAs) like sodium cholate $(\mathrm{NaCo})$, sodium deoxycholate, Span 60, Span 65, Span 80, Tween 20, Tween 60, Tween 80, and dipotassium glycyrrhizinate. ${ }^{8}$ This type of vesicle was firstly introduced

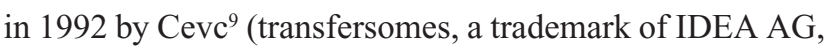
Munich, Germany), and it represents the first generation of UDV. The skin permeation and penetration of these elastic vesicles result from a synergic mechanism between the carrier properties and the permeation enhancement ability. Transfersomes can cross the skin layers by different mechanisms depending on their composition, in which these vesicles maintain their intact structure or fuse and mix with skin lipids. ${ }^{10}$ They can easily change their shape and cross the skin barrier due to the EA action in response to mechanical stress by relocating inside the vesicle to zones with smaller curvature, thus reducing the membrane elastic energy to a minimal level. ${ }^{11}$ Following this mechanism, transfersomes can easily squeeze through channels with one-tenth of the vesicles diameter, ${ }^{10}$ and cross the $\mathrm{SC}$ driven by an osmotic transdermal gradient. These elastic vesicles can only penetrate through skin layers under nonocclusive conditions in order to permit the excess water evaporation from the formulation and maintain this hydration gradient. Therefore,

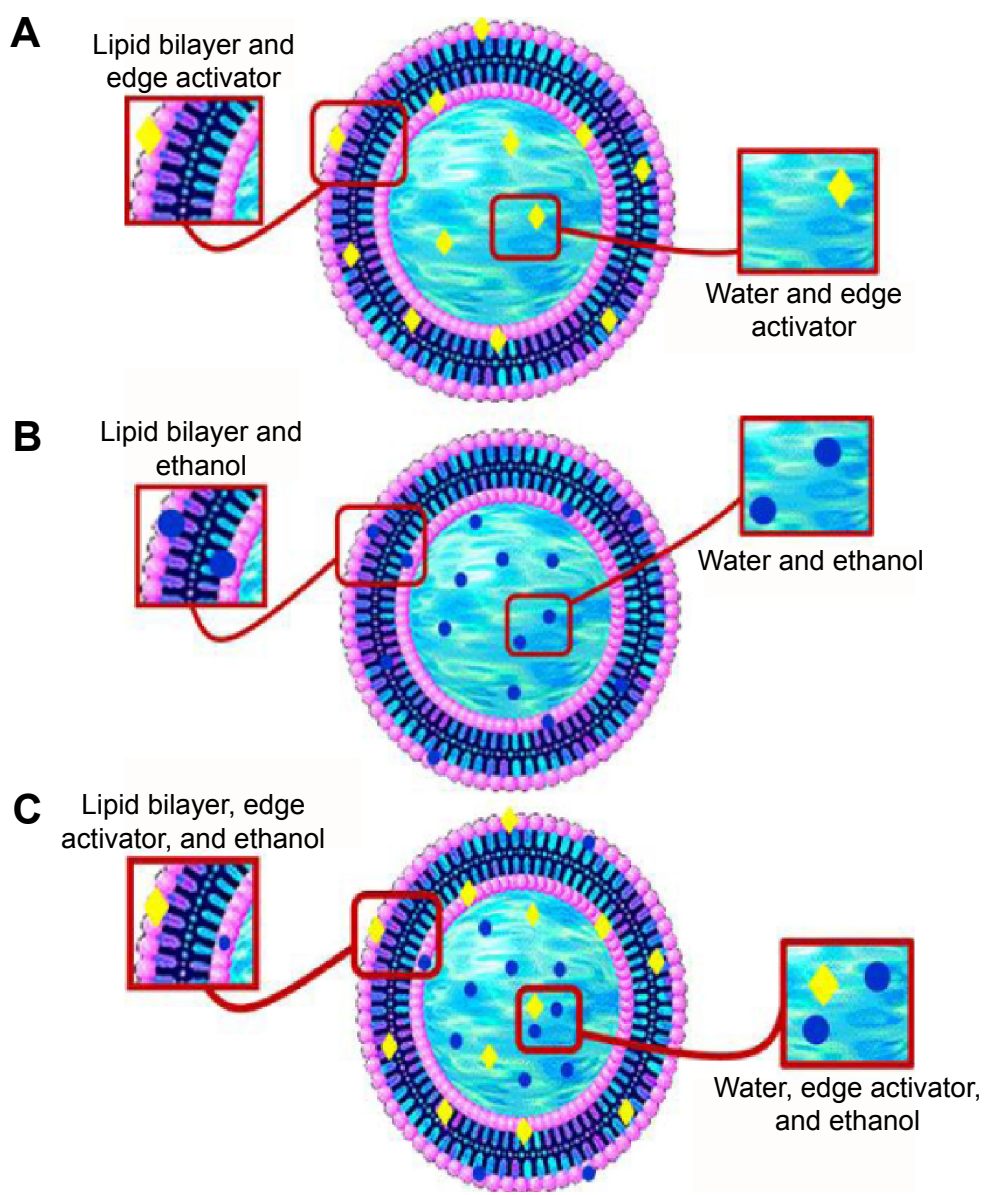

Figure I Schematic representation of ultradeformable vesicles.

Notes: (A) Transfersomes. (B) Ethosomes. (C) Transethosomes. Adapted from: Vinod KR, Kumar MS, Anbazhagan S, et al. Critical issues related to transfersomes - novel vesicular system. Acta Sci Pol Technol Aliment. 20 I 2; I ( I):67-82.7 
they pass in a nondiffusive way, which means that the penetration rate will not depend on the concentration gradient. ${ }^{12}$ Transfersomes also have the capability to protect the drug against rapid clearance to skin blood vessels and to promote the drug retention in the skin layers if needed. ${ }^{13}$

Transfersomes have been studied as carriers for dermal or transdermal delivery for different drugs. ${ }^{14-18}$ However, one main disadvantage of these vesicles corresponds to the difficulty of loading hydrophobic drugs into the vesicles without compromising their deformability and elastic properties. ${ }^{10}$ In general, transfersomes have been proven superior to conventional gel-state and liquid-state vesicles as well as conventional liposomes in terms of enhancement of drug permeation and interactions with the human skin. ${ }^{19}$

Ethosomes are special type of UDV developed by Touitou et al in 1997. ${ }^{20}$ Due to their size (approximately $150-200 \mathrm{~nm}$ ) and high deformability, they are also referred to as elastic nanovesicles. Ethosomal systems are vesicles consisting essentially of phospholipids, water, and a high quantity of ethanol. Phospholipids can be used at $0.5 \%-10 \%$ concentration range, and are obtained from natural semisynthetic and synthetic sources such as soybean and egg. Examples of phospholipids include phosphatidylethanolamine, phosphatidylinositol, phosphatidylcholine, and hydrogenated phosphatidylcholine. ${ }^{21}$ Ethanol can be used at 20\%-45\%, functioning as an efficient skin enhancer. ${ }^{1}$ This molecule interacts with the polar head group of the SC lipid molecules, leading to the reduction of the melting point of the SC lipids, thus increasing the fluidity of lipid bilayers and cell membrane permeability. ${ }^{3,5}$

In general terms, ethosomes could be considered a type of transfersome. The difference is that ethanol evaporates from the formulation once applied on the skin under nonocclusive conditions. In the case of transfersomes, the edge active molecules, most often surfactants, remain on the skin surface after water evaporation from the formulation.

The exact mechanism of skin permeation and penetration of Ethosomes is not totally understood. The synergistic combination of phospholipids and ethanol is thought to be responsible for a deeper drug loaded distribution and penetration into the skin layers. ${ }^{8}$ The elasticity of ethosomes associated to the disruption of the lipophilic SC barrier appears to be the most important contributor to its better performance for skin delivery compared to alcoholic solutions or classic liposomes. ${ }^{7,8,12}$

Transethosomes are lipid vesicles based on transfersomes and ethosomes. These novel UDV were firstly introduced by Song et al in 2012, ${ }^{22}$ and are characterized by having a high content of ethanol (up to 30\%) together with an EA.
Transethosomes may contain both advantages of transfersomes and ethosomes. Therefore, the mechanism of skin penetration might be a fusion of both mechanisms. ${ }^{22}$

Transethosomes have shown an irregular spherical shape and higher values in both vesicle elasticity and skin permeation/penetration studies. ${ }^{22}$ This fact may be due to the combination of ethanol and EA that causes a rearrangement in the lipid bilayer of these vesicles. ${ }^{22}$ Amphiphilic fluorescent probes or dyes (eg, rhodamine red, 6-carboxy fluorescence, fluorescence isothiocyanate, rhodamine-123, etc) with different physicochemical properties can also be incorporated into UDV for fluorescence microscopy studies. These studies contribute to further characterize the ability of UDV to penetrate through the skin (Figure 2). ${ }^{5}$

Generally, a hydrophilic molecule is expected to reside in the aqueous vesicle compartment; on the contrary, hydrophobic molecules are expected to interact with lipid membranes and incorporate in the carriers in a higher extent. In fact, most studies are limited to lipophilic actives and to the comparison between elastic and rigid vesicles., ${ }^{2,23}$ To the best of our knowledge, there is only one comparative study between transfersomes, ethosomes, and transethosomes. ${ }^{22}$

Charge interaction between actives and vesicles are also determinant for incorporation in vesicles. In structural terms, UDV are related to liposomes. Therefore, many of the techniques used for liposome characterization can be used for UDV as well. For liposomes, playing with different combinations of lipid type, charge, mixture and concentration, ionic strength of the hydration medium, and $\mathrm{pH}$ will affect the efficiency of actives incorporation and immobilization in vesicle type structures. On the other hand, UDV properties are responsible for

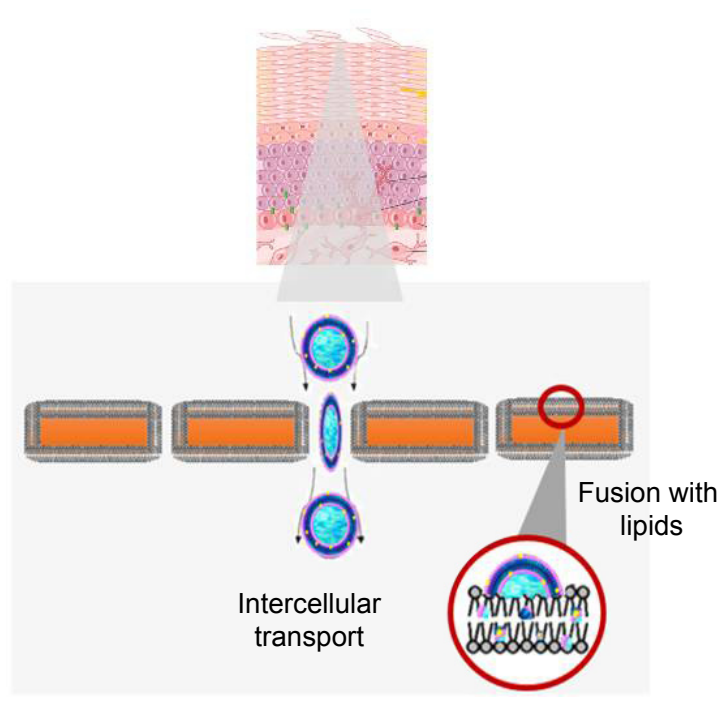

Figure 2 Schematic representation of ultradeformable vesicles permeation and penetration through the skin. 
membrane flexibility, and consequently, for vesicle deformability necessary for through-the-skin passagework. These properties are the result of a proper defined composition which is determinant for IE. The attempt to increase actives incorporation thus might compromise vesicles' deformability. In this study, the results of vitamin E and caffeine (Table S1) incorporated in three types of UDV (transfersomes, ethosomes, and transethosomes) are reported. The effect of incorporation capacity on drug permeation in not usually discussed. Thus, the role of the carrier on active-loaded UDV permeation will be addressed in this work.

\section{Materials and methods}

\section{Materials}

Caffeine was purchased from EMD Millipore (Billerica, MA, USA). $\alpha$-tocopherol, $\operatorname{Span}^{\circledR} 20, \mathrm{NaCo}$, and phosphotungstic acid (PTA) were purchased from Sigma-Aldrich Co. (St Louis, MO, USA). Soybean phosphatidylcholine (SPC) $\mathrm{S} 100^{\circledR}$ was purchased from Lipoid (Ludwigshafen, Germany). TAGAT CH $40^{\circledR}$ was purchased from Goldschimidt (Essen, Germany). Ultrapure water was obtained in a MILLI-Q System from EMD Millipore. All other reagents were of analytical grade.

\section{Methods}

\section{UDV formulations}

Different actives with distinct polarity (vitamin $E$ and caffeine) were incorporated in various UDV (transfersomes, ethosomes, and transethosomes) prepared with two different surfactants: $\mathrm{NaCo}$ or sorbitan laurate (Span 20) according to Table 1. The controls of each formulation (empty UDV) were also prepared. UDV formulations were prepared as described below. At the end, all formulations were filtered under pressure through track-etched polycarbonate membranes in order to obtain a final and similar size of approximately $150 \pm 50 \mathrm{~nm}$.

\section{Preparation of transfersomes - method A}

Transfersomes were prepared by adding the active compound to the mixture of SPC, bilayer softening agent (surfactant), and purified water. This mixture was stirred for a period of at least 7 days. The formulations were always protected from light and air exposure.

\section{Preparation of ethosomes - method B}

Ethosomes were prepared according to the classical "cold method". 3,5 Briefly, the active compound was previously dissolved in the mixture of pure ethanol and SPC, stirred, and immersed in a water bath maintained at $30^{\circ} \mathrm{C} \pm 2^{\circ} \mathrm{C}$. After achieving the active dissolution, purified water was added drop by drop through a syringe needle inserted in the bottle cap. The formulation continued to be stirred for an additional time of 5 minutes at the same temperature, after which it was kept at room temperature for about 30 minutes.

\section{Preparation of transethosomes}

Transethosomes were prepared according to the methods A and $\mathrm{B}$ above described.

\section{Characterization of UDV formulations \\ Visualization of vesicles by transmission electron microscopy}

Transfersomes, ethosomes, and transethosomes were visualized using the electron microscope H-8100 from Hitachi Ltd. (Tokyo, Japan). All samples $(10 \mu \mathrm{L})$ were previously diluted with $1 \mathrm{~mL}$ of distilled water. Then, a drop of the diluted sample was left to dry on a microscopic copper-coated grid (transmission electron microscopy grid support films of Formvar/carbon, 200 mesh $\mathrm{Cu}$ ). After drying completely, another drop of a $1 \%$ aqueous solution of PTA was added for negative staining. Forty-five seconds later, the excess solution was wiped with filter paper. Then, the specimen was viewed under the microscope with an accelerating voltage of $75 \mathrm{kV}$ and at different magnifications.

\section{Size and zeta potential}

The mean size and polydispersity index (PDI) of UDV were determined by dynamic light scattering with Zetasizer Nano-S equipment (Malvern Instruments, Malvern, UK).

Table I Ultradeformable vesicle composition

\begin{tabular}{|c|c|c|c|}
\hline Composition (\% w/v) & Transfersomes & Ethosomes & Transethosomes \\
\hline Active compound & 1 & 1 & I \\
\hline SPC & 10 & 10 & 10 \\
\hline \multirow[t]{4}{*}{ Surfactant } & Sodium cholate ( $\mathrm{NaCo}): 2.3$ & - & Sodium cholate ( $\mathrm{NaCo}): 2.3$ \\
\hline & (3.75: I, molar ratio SPC: $\mathrm{NaCo}$ ) or & & (3.75: I, molar ratio SPC: $\mathrm{NaCo}$ ) or \\
\hline & Sorbitan laurate $\left(\operatorname{Span}^{\circledR} 20\right): 1.8$ & & Sorbitan laurate $\left(\operatorname{Span}^{\circledR} 20\right)$ : 1.8 \\
\hline & (2:I, molar ratio SPC: Span 20) & & (2:I, molar ratio SPC: Span 20) \\
\hline Ethanol & - & 30 & 30 \\
\hline Purified water & Qs 100 & Qs 100 & Qs 100 \\
\hline
\end{tabular}

Abbreviations: Qs, quantum satis; SPC, soybean phosphatidylcholine. 
PDI less than 0.2 indicates a homogenous and monodisperse population. Zeta potential was determined by laser-Doppler anemometry with Zetasizer Nano-Z equipment (Malvern instruments)

For both measurements, $10 \mu \mathrm{L}$ of transfersome, transethosome, and ethosome formulations were diluted with purified water.

\section{Active high-performance liquid chromatography quantification}

The quantification of vitamin $\mathrm{E}$ and caffeine was performed using a high-performance liquid chromatography (HPLC) system (Tokoy, Shimadzu, Japan) with a SPD-10A UV-VIS detector according to Table 2. This methodology was previously validated as reported in the literature. ${ }^{24-26}$

\section{SPC quantification}

SPC concentration was determined by an enzymatic and colorimetric method (Phospholipids kit; Spinreact, Sant Esteve de Bas, Spain) at $505 \mathrm{~nm}$ and $37^{\circ} \mathrm{C}$.

\section{Determination of incorporation parameters}

The initial formulation was diluted and centrifuged at $180,000 \times g, 15^{\circ} \mathrm{C}$ for 4 hours (Beckman Optima XL-90, Ultracentrifuge, GMI, Ramsey, Minnesota, USA). After this time, the supernatant was removed and the precipitate was suspended with purified water. IE, active entrapment yield, and active loading were calculated according to the following equations:

$$
\begin{gathered}
\text { IE }(\%)=\frac{[\text { active }]_{\text {final }} \times[\text { lipid }]_{\text {initial }}}{[\text { active }]_{\text {initial }} \times[\text { lipid }]_{\text {final }}} \times 100 \\
\text { Active entrapment yield }=\frac{[\text { Active }]_{\text {final }}}{[\text { Active }]_{\text {initial }}} \times 100 \\
\text { Active loading }=\frac{[\text { Active }]_{\text {before or after centrifugation }}}{[\text { Lipid }]_{\text {before or after centrifugation }}}
\end{gathered}
$$

\section{Pressure-driven transport}

The flow of the vesicles was measured by pressure-driven transport. Briefly, vesicles diluted at $1 \%$ lipid final concentration were forced to pass through $30 \mathrm{~nm}$ pore size track-etched polycarbonate membranes under 0.6 MPa pressure, created by a nitrogen stream, during at least 5 minutes. The suspension was collected in a container on a Sartorius LA620P scale (Data Weighing Systems, Inc., Elk Grove, IL, USA). The data were collected with the Wedge software for Windows (TAL Technologies Inc., Philadelphia, PA, USA).
Table 2 Experimental conditions for HPLC quantification of the active compounds tested

\begin{tabular}{lll}
\hline Active compounds & Caffeine & Vitamin E \\
\hline Wavelength $(\mathrm{nm})$ & 272 & 291 \\
Retention time $(\mathrm{min})$ & 2.7 & 4.6 \\
Run time $(\mathrm{min})$ & 10 & 10 \\
Mobile phase & Water:methanol $(60: 40, \mathrm{~V} / \mathrm{V})$ & Methanol \\
Flow rate $(\mathrm{mL} / \mathrm{min})$ & $\mathrm{I}$ & \\
Injection loop $(\mu \mathrm{L})$ & 20 & Lichrospher $100 \mathrm{RP}-\mathrm{I} 8, \mathrm{I} 25 \times 4 \mathrm{~mm}, 5 \mu \mathrm{m}$ \\
\hline
\end{tabular}

Abbreviation: HPLC, high-performance liquid chromatography; min, minute.

\section{Viscosity measurement}

The viscosity of UDV formulations was determined by using a Brookfield ${ }^{\circledR}$ Digital Viscometer (Model DV-II) with a spindle number 21 at $5 \mathrm{rpm}\left(23^{\circ} \mathrm{C} \pm 2^{\circ} \mathrm{C}\right)$. Readings were taken after 30 seconds.

\section{Topical Delivery of UDV}

\section{Release study}

Release studies have been performed using vertical Franz diffusion cells (diffusion area of $1.0 \mathrm{~cm}^{2}$ ) with hydrophilic polysulfone membranes (Tuffryn ${ }^{\circledR}$; Pall Corporation, Port Washington, NY, USA) after its saturation in receptor phase (RP) for 30 minutes. The RPs were previously studied in order to ensure the sink conditions. A higher solubilization of Caffeine and vitamin E was obtained using a $0.9 \%(\mathrm{~m} / \mathrm{v})$ $\mathrm{NaCl}$ aqueous solution ${ }^{27}$ and $0.1 \%(\mathrm{~m} / \mathrm{v})$ Tagat $^{\circledR}$ in 0.01 $\mathrm{M}$ saline phosphate buffer ( $\mathrm{pH} 7.4$ ), respectively. The RP was maintained at $32^{\circ} \mathrm{C}-37^{\circ} \mathrm{C}$ under stirring (Julabo U3 Thermostat and Multimagnetic stirrer SBS ${ }^{\circledR}$; Labexchange, Paris, France).

About $0.5 \mathrm{~g}$ of each formulation was applied in the donor compartment under nonocclusive conditions. Attending to the lowest IE obtained for the hydrophilic active (caffeine)loaded UDV, the respective solution controls were also studied. The solution composition was similar to UDV, except for the absence of lipid.

Samples of $200 \mu \mathrm{L}$ were collected after 1, 2, 3, 4, 5, and 6 hours according to international guidelines ${ }^{28-30}$ and the same volume was replaced with fresh RP kept at the same temperature. These samples were quantified by HPLC as previously described for each active. Data $(n=6)$ was expressed as cumulative amount of active (M) permeated through the membrane filter, considering the total amount as the active dose assayed in each formulation according to Equation 4.

$\mathrm{M}=\frac{\left(\text { Conc. }_{\text {measured }} \times \text { Volume }_{\mathrm{RP}}\right)+\sum\left(\text { Conc. }_{\text {measured }} \times \text { Volume }_{\text {aliquot }}\right)}{\text { Membrane area }}$ 


\section{Permeation and penetration studies}

In vitro skin permeation study was performed according to the method described by OECD Guideline $428^{28}$ at the same conditions as described before, except for the use of fresh pig ear skin (dermatomized to $500 \mu \mathrm{m}$ ). Vitamin E- and caffeineloaded UDV formulations as well as caffeine solution controls $(500 \mu \mathrm{L})$ were spread over the skin $\left(0.68 \mathrm{~cm}^{2}\right)$ in contact with $3.5 \mathrm{~mL}$ of RP, and 24 hours later, the skin samples were rinsed to remove excess formulation and dried with filter paper. After the skin samples had been attached and fixed on a smooth surface, the SC was removed using 20 adhesive tapes (Scotch ${ }^{\circledR} ; 3 \mathrm{M}, \mathrm{S}$. Paulo, Brazil). In order to improve the reproducibility of the tape stripping technique, a cylinder $(2 \mathrm{~kg}$ ) on a foam and an acrylic disk (both with an area of $5.73 \mathrm{~cm}^{2}$ ) were used resulting in a pressure of $349.3 \mathrm{~g} / \mathrm{cm}^{2}$ applied for 10 seconds for each tape. All the tapes with the $\mathrm{SC}$ removed and the remaining skin (viable epidermis and dermis) were cut into small pieces used for the extraction process, which had been previously validated ( $>80 \%$ recovery). In this extraction process, $3-5 \mathrm{~mL}$ of methanol were added to both SC tapes and epidermis/dermis (ED) pieces. These samples were stirred for 1 minute in a vertical mixer, sonicated for 15 minutes, and centrifuged at $400 \times g$ for 5 minutes. After filtration $(0.45 \mu \mathrm{m})$, the supernatant $(50 \mu \mathrm{L})$ was injected on HPLC to quantify the amount of vitamin $\mathrm{E}$ and caffeine retained in each skin layer.

\section{Statistical analysis}

The results were reported as mean \pm standard deviation of at least three measurements per formulation. The results were statistically analyzed by analysis of variance using SigmaPlot 11.0 software $^{\circledR}$. The differences were considered statistically significant when $P<0.05$.

\section{Results and discussion}

\section{Characterization of UDV formulations}

The macroscopic and microscopic appearances of UDV formulations (empty controls) are represented in Figures 3 and 4. It was observed that both transfersomes and ethosomes were

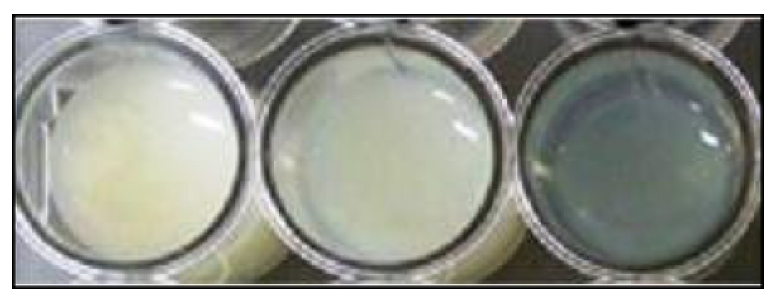

Figure 3 Macroscopic appearance of ultradeformable vesicles formulations. Note: Transfersomes, ethosomes, and transethosomes (from left to right). whitish, and transethosomes were the most translucent formulation due to the presence of both ethanol and surfactant $(\mathrm{NaCo})$ in the formulation composition. Regarding the transmission electron microscopy imaging, PTA was used as the negative stain for these samples since it is an electron dense or opaque reagent for electrons. In fact, it reacted well with the vesicles allowing visualizing and discerning the vesicles' membrane and lamellae, especially in the case of transethosomes (probably due to the presence of ethanol and less turbidity). In contrast, transfersomes were quite difficult to visualize since a lower contrast was obtained. Although all vesicles appeared to have a multilamellar spherical form, other forms were also observed in some aggregates (mainly formed after the drying process). This was possible due to the high deformability of the vesicles' membrane which permits them to adapt its form to the surrounding space. In addition, all vesicles have a diameter of $150 \pm 50 \mathrm{~nm}$, with transethosomes being the smallest vesicles, as further confirmed by dynamic light scattering.

The results of the tested parameters used to characterize all UDV formulations are presented in Table 3. An easier comparability between these formulations was achieved by standardizing all procedures like the vesicles' composition or their preparation (eg, number of filtrations, pore filter, etc) and characterization methods, including the respective formulation controls.

Regarding the vesicles' size, all formulations showed values within the expected range (100-200 nm), except transethosomes prepared by method A, for which diameter was smaller than $100 \mathrm{~nm}$ in contrast to that obtained by vesicles prepared by method $B$. This was probably due to differences in stirring time: while the formulations prepared by method B ("ethosomal" method) were stirred only during the addition of water, the formulations prepared by method A ("transfersomal" method) were stirred for 7 days which probably led to a more compact structural rearrangement of surfactant and ethanol molecules, with a consequent decrease of the vesicles size in the latter case. Therefore, only transethosomes prepared by method B with a similar and comparable size with the other formulations were used for topical delivery experiments.

Concerning the PDI, a value of $<0.2$ (homogeneous population) was obtained for all formulations, except transfersomes with vitamin $\mathrm{E}$ (PDI =0.428). This value may be explained by the specific location of vitamin $\mathrm{E}$ in the vesicles' membrane due to its lipophilicity, and the higher IE which contributes to increase the vesicles size and PDI especially when compared with the formulation control (empty transfersomes). 
Transfersomes
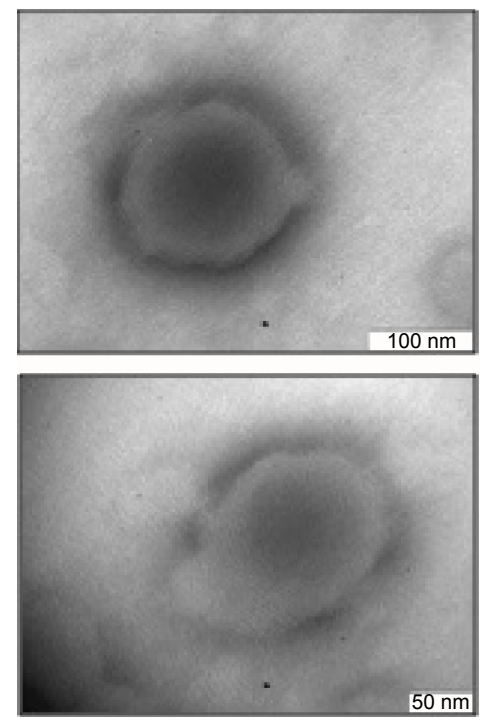

Ethosomes
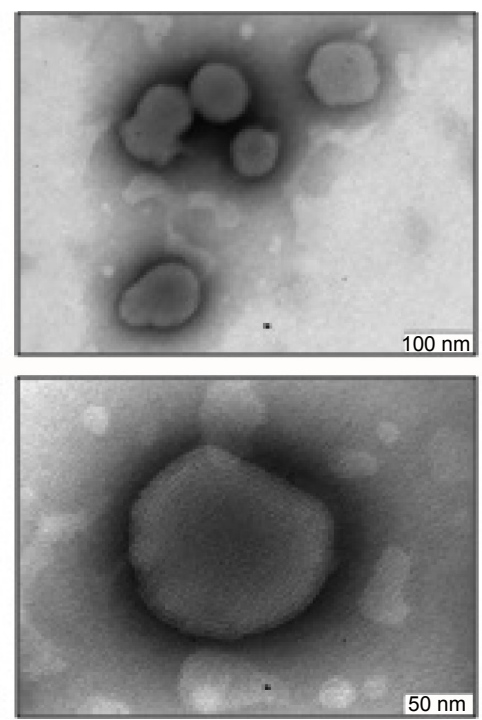

Transethosomes
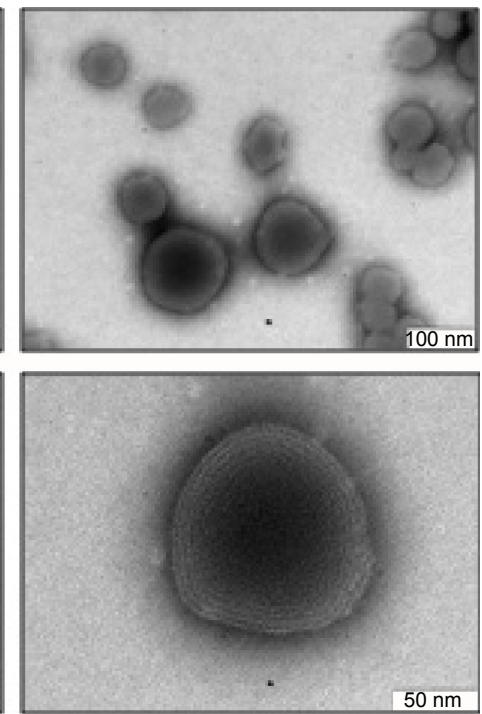

Figure 4 Microscopic appearance of ultradeformable vesicle formulations obtained by transmission electron microscopy.

Zeta potential is an important physical parameter for predicting the vesicles' stability. ${ }^{31}$ All UDV formulations showed a negative zeta potential as expected. The formulations containing $\mathrm{NaCo}$ had the highest (modular) zeta potential due to the negative charge of this EA in contrast to the nonionic Span 20. Although SPC lipid has a zwitterionic behavior, it is important to consider the negative charge of the phosphate groups of SPC phospholipids which also contributed to the negative surface charge of the vesicles. ${ }^{32}$ Finally, the contribution of both caffeine and vitamin E to the zeta potential was almost negligible when compared with the respective UDV control.

The IE as well as active entrapment yield and active loading were much higher for vitamin E- than for caffeineloaded UDV as expected according to the respective $\log \mathrm{P}$ (8.84 versus -0.55 , respectively). The IE was low $(<10 \%)$ and similar for caffeine-loaded transfersomes, transethosomes (prepared by either method A or B with both surfactants), and ethosomes (prepared by adding this active in either ethanol or aqueous phase [data not shown]). In this last case, the active entrapment yield remained around $3 \%$ because most of aqueous phase remains outside the vesicles. The hydrophilicity of caffeine may reduce the encapsulation efficiency to the inner aqueous compartment of UDV in contrast to the lipophilic vitamin E which is easily incorporated in the vesicles' membrane resulting in a higher IE ( $>77 \%)$. This result is consistent with the values obtained by Pham et a ${ }^{33}$ for caffeine-loaded liposomes and niosomes formulations.
SPC yield was high ( $>65 \%$ ) for all UDV formulations proving that there was minimal vesicle loss during the centrifugation step. Thus, this parameter did not influenced the IE obtained.

Viscosity is an important parameter to further characterize the physical behavior of the developed formulations, especially regarding the topical application. All formulations showed a similar viscosity being higher in the presence of ethanol. Ethanol molecules contain both hydrophobic and hydrophilic groups involving two hydrogen bonds, which leads to a network differently structured than water. In the case of ethanolic aqueous solutions, alcohol molecules firstly fill the voids of the hydrogen-bond network of the water structure and "fortify" the structure due to the hydrogen bonds between the hydroxyl oxygen of alcohol and water. ${ }^{34}$ This explains the increase of the viscosity of formulations containing ethanol. Although UDV formulations were suitable for topical application, other dosage forms could be considered depending on the application site. For example, eyebrows and neck require especial care when applying liquid formulations. The modification of the final formulation rheology could be achieved by the inclusion of UDV suspension in a gel. This approach is commonly found in the literature. ${ }^{13,35}$

The pressure-driven transport of UDV formulations is represented in Table 3 and Figure 5.

Considering all the results, the following order for UDV flux was obtained: transethosomes (TE) $>$ ethosomes (E) $\geq$ transfersomes $(\mathrm{T})$ for both vitamin $\mathrm{E}$ and caffeine formulations. The difference between transethosomes and the other UDV was 


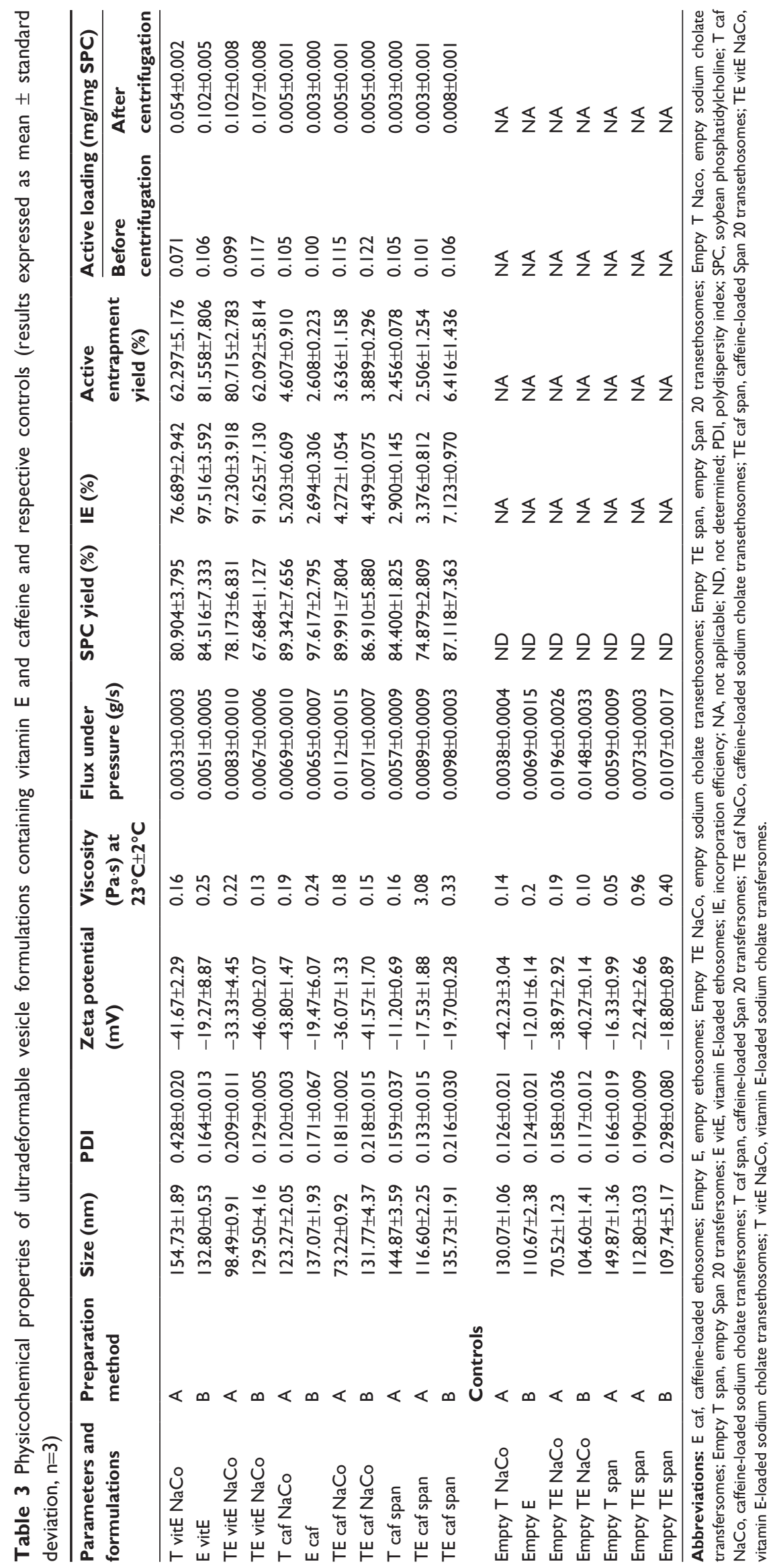




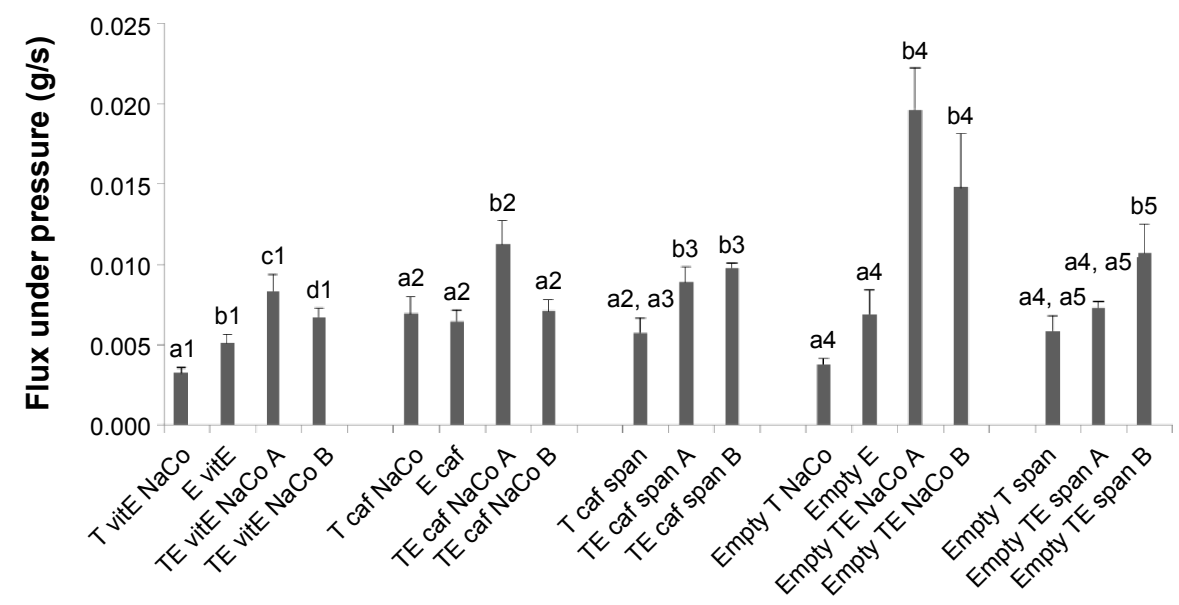

Figure 5 Flux of the different formulations after pressure filtration expressed as mean \pm standard deviation $(\mathrm{g} / \mathrm{s})$.

Notes: $A$ and $B$ at the end of the legend refer to the method employed for the vesicles preparation, method A or method B, respectively. For each formulation, the flux was performed in triplicate $(n=3)$. Statistical analysis: One Way Anova with All Pairwise Multiple Comparison Procedures; means with different letters (a,b,c) and different numbers are significantly different $(P<0.05)$. The letters are also numerated according to each group.

Abbreviations: $E$ caf, caffeine-loaded ethosomes; empty E, empty ethosomes; empty TE NaCo, empty sodium cholate transethosomes; empty TE span, empty Span 20 transethosomes; empty T Naco, empty sodium cholate transfersomes; empty T span, empty Span 20 transfersomes; E vitE, vitamin E-loaded ethosomes; T caf NaCo, caffeineloaded sodium cholate transfersomes; T caf span, caffeine-loaded Span 20 transfersomes; TE caf NaCo, caffeine-loaded sodium cholate transethosomes; TE caf span, caffeineloaded Span 20 transethosomes; TE vitE NaCo, vitamin E-loaded sodium cholate transethosomes; T vitE NaCo, vitamin E-loaded sodium cholate transfersomes.

statistically different $(P<0.05)$ for all tested formulations, especially the controls (empty UDV) prepared with $\mathrm{NaCo}$. This is easily explained by the presence of both ethanol and surfactant in transethosomes composition, acting synergically on the flexibility of the membranes and thus on the vesicles' deformability. The same order was obtained in other previous experiments for elasticity index determination (data not shown).

\section{Topical delivery}

The release profiles of vitamin E UDV formulations are shown in Figure 6.

The release profile was consistent with the flux data, as theoretically expected: TE $>\mathrm{E}>\mathrm{T}$ with significant differences
$(P<0.05)$, especially for transethosomes and ethosomes. Transethosomes are the most deformable vesicles, easily changing their conformation and allowing a higher membrane passage. In addition, a sustained and controlled release as already reported for UDV, mainly transfersomes, was also observed. ${ }^{9,36}$ The passage of vesicles and active to the RP was confirmed by dynamic light scattering and HPLC, respectively. Although it is not usual to analyze the donor compartment, the active was assayed in both donor and receptor compartments at each hour considering the nonocclusive conditions necessary for this study. However, the active amount did not increase along time in donor phase in contrast to RP because the evaporation rate was lower than the release rate.
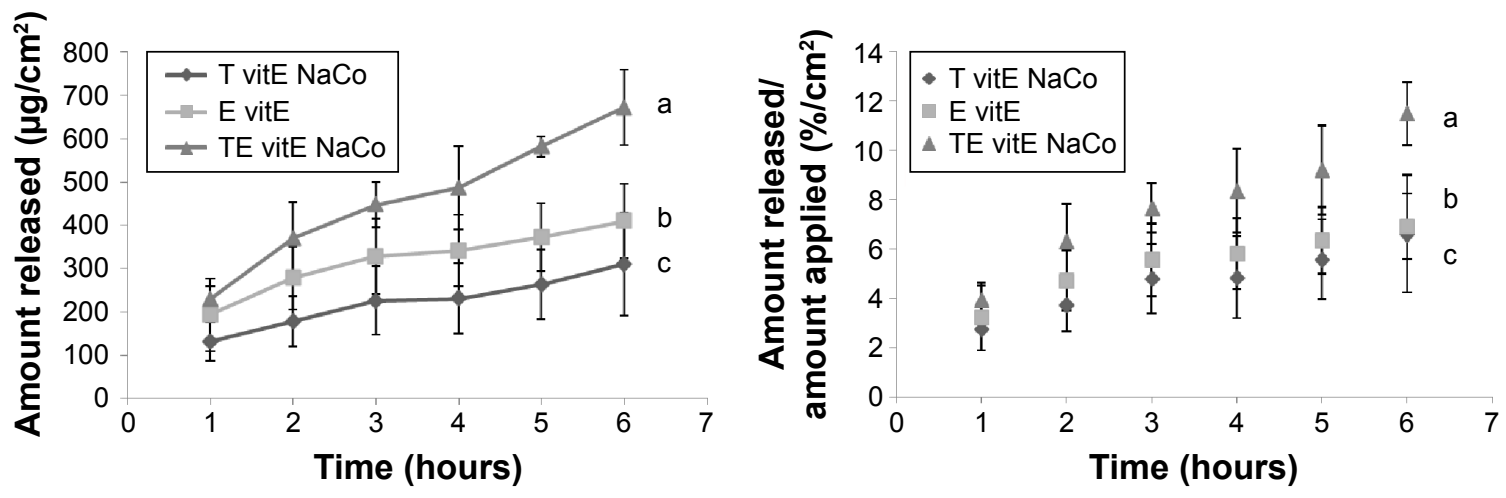

Figure 6 Cumulative amount of vitamin E ultradeformable vesicle formulation released over 6 hours, expressed as mean (absolute value and \%) \pm standard deviation. Notes: Data were collected from six samples ( $n=6$ per formulation) at each hour using Franz cells. Statistical analysis: two-way analysis of variance with duplicates and all pairwise multiple comparison procedures; means with different letters $(a, b, c)$ are significantly different $(P<0.05)$.

Abbreviations: $\mathrm{E}$ vitE, vitamin E-loaded ethosomes; $\mathrm{TE}$ vitE $\mathrm{NaCo}$, vitamin E-loaded sodium cholate transethosomes; $\mathrm{T}$ vitE $\mathrm{NaCo}$, vitamin E-loaded sodium cholate transfersomes. 
The release profiles of caffeine UDV formulations (prepared with $\mathrm{NaCo}$ ) are represented in Figure 7 . In contrast to vitamin $\mathrm{E}$, the release profiles of caffeine UDV formulations were much higher, and showed the following order: $\mathrm{T}>\mathrm{E}>\mathrm{TE}$ with significant differences $(P<0.05)$. The same order was observed for caffeine UDV formulations prepared with Span 20 (data not shown) and caffeine solution controls but with lower differences between them in the latter case. Comparing these solution controls with the respective UDV formulations, the release was significantly higher for the controls except transfersome control solution, for which release was statistically similar to caffeine-loaded transfersomes. The similar order observed was due to the low IE of caffeine in all tested UDV. Therefore, the results obtained might be more related with caffeine solubility and thermodynamic activity in each UDV formulation rather than UDV deformability.
In fact, the solubility of caffeine in water and in ethanol is $0.105 \mathrm{M}$ and $0.029 \mathrm{M}$, respectively.

\section{Permeation and penetration studies}

Although vitamin E was detected in RP after 24 hours (permeation study) for all three UDV formulations, its concentration $(0.085-0.117 \mu \mathrm{g} / \mathrm{mL})$ was neglected since it was lower than the limit of quantification $(1 \mu \mathrm{g} / \mathrm{mL})$.

The results of the penetration study are represented in Figure 8 .

The following order of vitamin E-loaded UDV retained in SC was obtained: $\mathrm{T}>\mathrm{E} \geq \mathrm{TE}$, and the opposite order was observed for $\mathrm{ED}$ retention ( $\mathrm{TE}>\mathrm{T} \geq \mathrm{E}$ ) expressed as $\% / \mathrm{cm}^{2}$. The retention profile order of vitamin E-loaded UDV formulations at deeper skin layers was in accordance with the respective release profile and vesicles' deformability before.
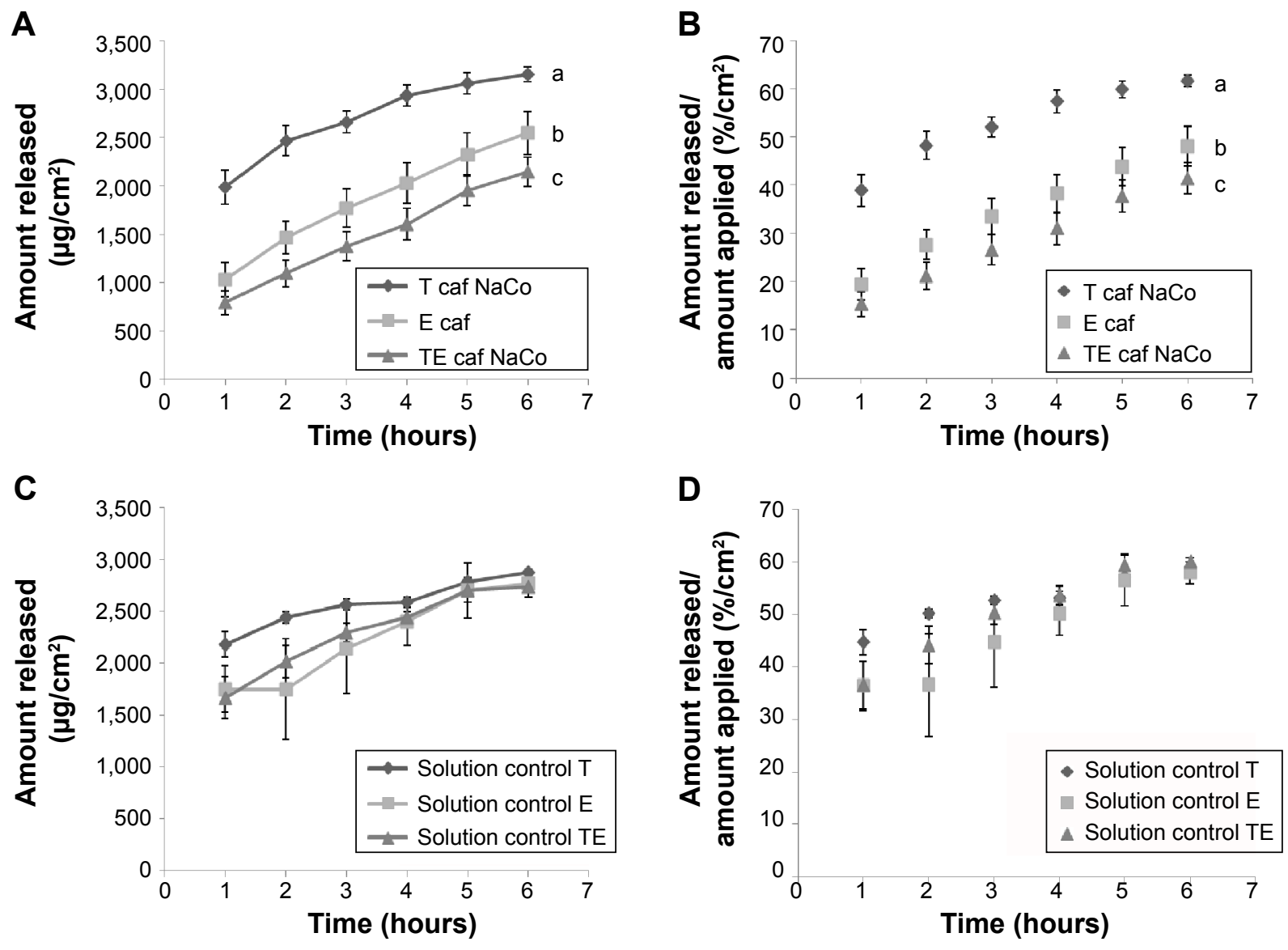

Figure 7 (A) Cumulative amount of caffeine UDV formulation (prepared with sodium cholate) released over 6 hours, expressed as mean \pm SD. ( $\mathrm{n}=6$ per formulation). (B) Cumulative amount of caffeine UDV formulation (prepared with sodium cholate) released over 6 hours relative to the applied amount, expressed as mean \pm SD ( $n=6$ per formulation). (C) Cumulative amount of Caffeine solution controls released over 6 hours, expressed as mean \pm SD ( $n=3$ per control). (D) Cumulative amount of caffeine solution controls released over 6 hours relative to the applied amount, expressed as mean \pm SD ( $n=3$ per control).

Notes: Statistical analysis: two-way analysis of variance with duplicates and all pairwise multiple comparison procedures; means with different letters (a,b and c) are significantly different $(P<0.05)$.

Abbreviations: $\mathrm{E}$ caf, caffeine-loaded ethosomes; Solution Control E, control solution for ethosomes; Solution Control T, control solution for transfersomes; Solution Control TE, control solution for transethosomes; SD, standard deviation; $\mathrm{T}$ caf $\mathrm{NaCo}$, caffeine-loaded sodium cholate transfersomes; TE caf $\mathrm{NaCo}$, caffeine-loaded sodium cholate transethosomes; UDV, ultradeformable vesicles. 

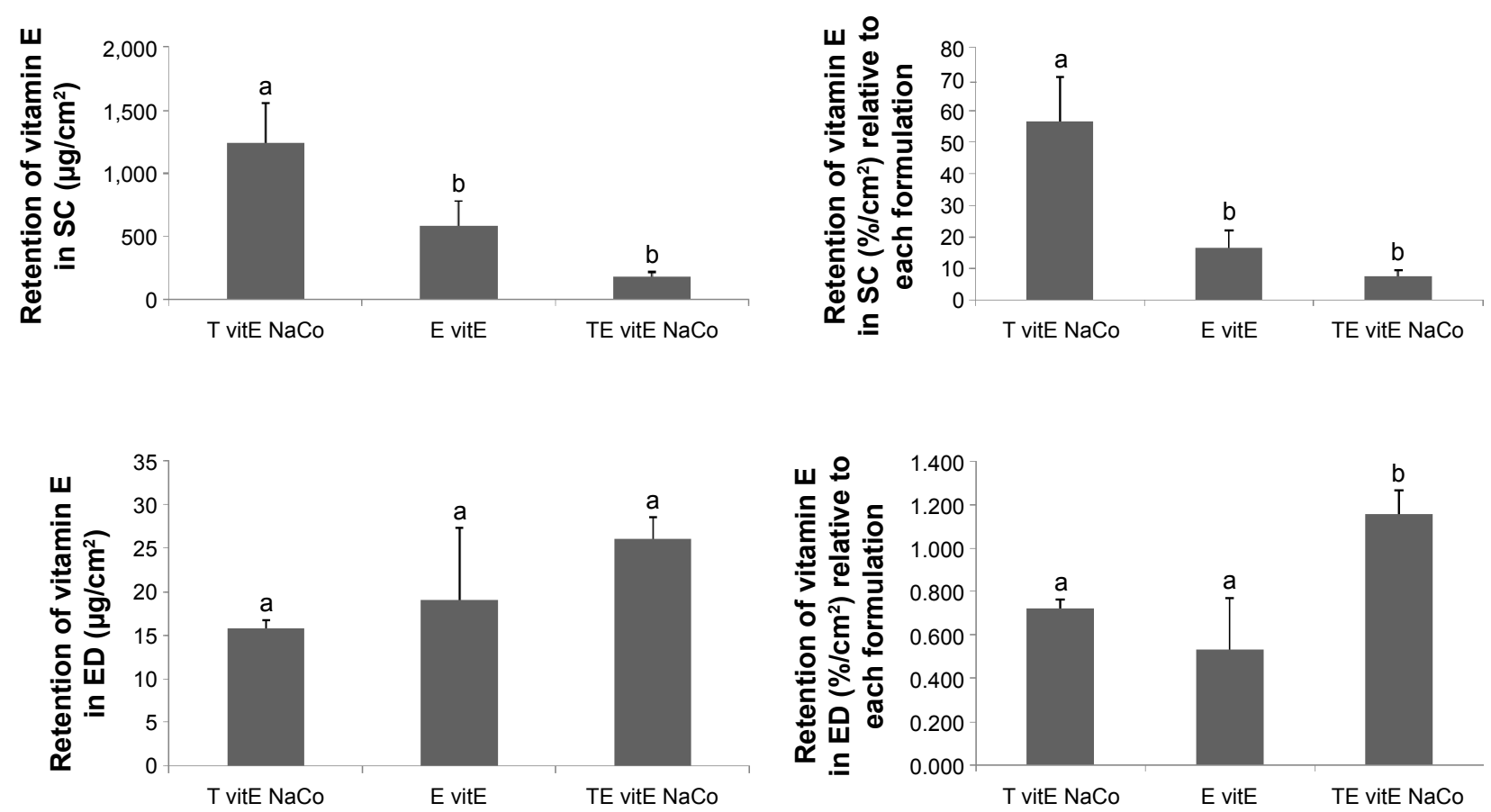

Figure 8 Retention of vitamin E ultradeformable vesicle formulations in SC and ED after 24 hours, expressed as mean $\left(\mu g / \mathrm{cm}^{2}\right.$ or $\left.\% / \mathrm{cm}^{2}\right) \pm$ standard deviation $(\mathrm{n}=3$ per formulation).

Notes: Statistical analysis: one-way analysis of variance with all pairwise multiple comparison procedures (Holm-Sidak method); means with different letters are significantly different $(P<0.05)$.

Abbreviations: ED, epidermis plus dermis; E vitE, vitamin E-loaded ethosomes; SC, stratum corneum; TE vitE NaCo, vitamin E-loaded sodium cholate transethosomes; $\mathrm{T}$ vitE $\mathrm{NaCo}$, vitamin E-loaded sodium cholate transfersomes.

This may be attributed to the fusion of these vesicles with skin lipids and the active release along the penetration pathway, resulting in a depot effect. In particular, this effect could be higher in the presence of ethano ${ }^{22,23,37-39}$ which increases the skin permeability by intercalation into the polar head group of skin lipids. The synergistic mechanism between ethanol, surfactant, vesicles, and skin lipids is responsible for a higher skin penetration of transethosomes. In addition, the deeper penetration of vitamin E could also be associated to the higher vitamin E IE in UDV containing ethanol.

Lipophilic molecules such as vitamin E, highly incorporated in lipid carriers, are usually used for topical delivery studies. In this study, we have also used caffeine, a hydrophilic molecule that is not expected to be incorporated in liposome-like structures to a great extent, to evaluate if the non-incorporated active fraction (present in a higher percentage than the incorporated fraction) would be more released and accumulated in deeper skin layers than the respective control solution. Regarding the formulations with caffeine (Figure 9), all tested UDV formulations (including the respective solution controls) permeated through the skin after 24 hours. The smaller molecular size and $\log$ P of caffeine contributed to a higher skin permeation compared to vitamin E correspondent to the non-incorporated fraction of UDV formulations.

It was initially hypothesized that UDV formulations might smooth the progress of the non-incorporated active fraction through the skin along with its penetration. However, it was observed that the solution controls contributed to both higher skin retention and permeation profiles of caffeine than the respective UDV formulations possibly due to its low IE and, on the other hand, to the lower viscosity, lipids absence, and probably higher caffeine dissolution of solution formulations. Nevertheless, no statistical differences were found for caffeine-loaded UDV containing ethanol and caffeine-loaded transfersomes versus solution controls for skin permeation $\left(\% / \mathrm{cm}^{2}\right)$ and all skin experiments, respectively. There were also no significant differences between UDV formulations, except for caffeine-loaded ethosomes whose ED retention and permeation profile was higher.

\section{Conclusion}

This study aimed to compare the characteristics of different UDV and their influence on skin delivery of caffeine and vitamin E. The release profile is dependent on the actives' chemical properties and their IE in UDV formulations. 

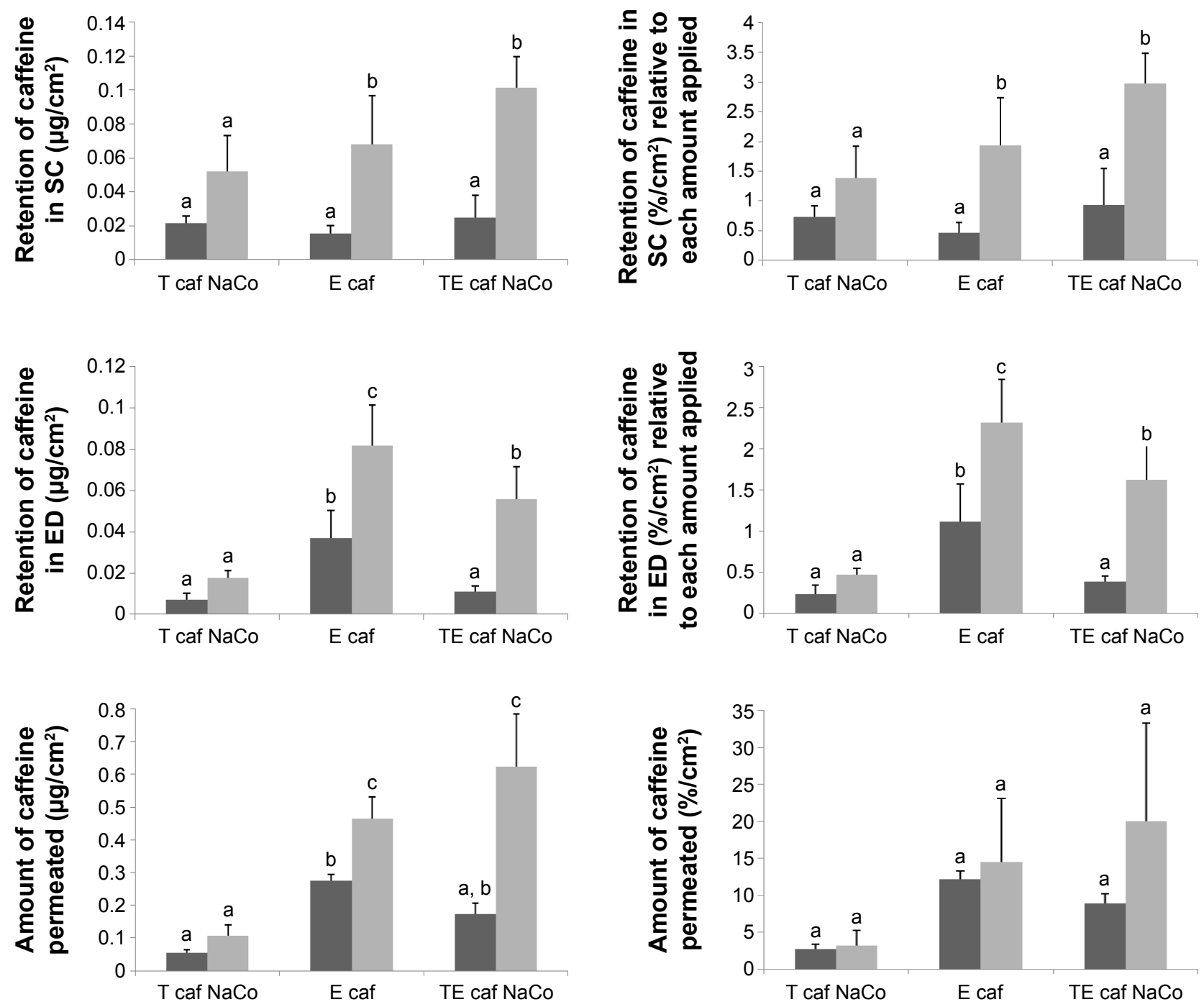

UDV Solution control

Figure 9 Retention of caffeine UDV formulations, and the respective solutions controls in SC and ED and skin permeation after 24 hours, expressed as mean $\left(\mu g / \mathrm{cm}^{2}\right.$ or $\left.\% / \mathrm{cm}^{2}\right) \pm$ standard deviation ( $\mathrm{n}=3$ per formulation).

Notes: Statistical analysis: one-way analysis of variance with all pairwise multiple comparison procedures (Holm-Sidak method) between each group (UDV versus respective controls and transfersomes versus ethosomes versus transethosomes); means with different letters are significantly different $(P<0.05)$.

Abbreviations: E caf, caffeine-loaded ethosomes; ED, epidermis plus dermis; SC, stratum corneum; T caf $\mathrm{NaCo}$, caffeine-loaded sodium cholate transfersomes; TE caf $\mathrm{NaCo}$, caffeine-loaded sodium cholate transethosomes; UDV, ultradeformable vesicles.

A sustained release will be more easily obtained for higher incorporated molecules, such as vitamin E. Even with low IE, it was also possible to achieve a good skin retention and penetration of caffeine-loaded UDV in comparison to solution controls.

Considering the results obtained here, transethosomes are the liposome-like vesicles with more advantages for deeper skin penetration as measured by deformability and permeation experiments. In addition, this vesicular formulation is quite easy to scale up, which constitutes a great advantage for industrial purposes.
Here we proved that all these UDV are useful as skin delivery systems by acting as drug carriers as well as permeation enhancers, and are capable of retaining the active molecules accessible within different skin layers, under certain conditions. These data suggest that the formulation of actives in UDV may be performed in a case-by-case manner.

\section{Acknowledgments}

All authors acknowledge Carla Euletério and Isabel Nogueira for technical support and TEM imaging, respectively. 
All authors also acknowledge Laboratório Edol - Produtos Farmacêuticos, SA and Sopalmeira, Lda. for financial support.

\section{Author contributions}

All authors contributed toward data analysis, drafting and revising the paper and agree to be accountable for all aspects of the work.

\section{Disclosure}

The authors report no conflicts of interest in this work.

\section{References}

1. Manosro A, Jantrawut P, Khositsuntiwong N, Manosroi W, Manosroi J. Novel Elastic Nanovesicles for Cosmeceutical and Pharmaceutical Applications. Chiang Mai J Sci. 2009;36(2):168-178.

2. Vanić Ž, Hafner A, Bego M, Škalko-Basnet N. Characterization of various deformable liposomes with metronidazole. Drug Dev Ind Pharm. 2013;39(3):481-488

3. Touitou E, Dayan N, Bergelson L, Godin B, Eliaz M. Ethosomes novel vesicular carriers for enhanced delivery: characterization and skin penetration properties. J Control Release. 2000;65(3):403-418.

4. Jain S, Tiwary AK, Sapra B, Jain NK. Formulation and evaluation of ethosomes for transdermal delivery of lamivudine. AAPS PharmSciTech. 2007;8(4):E111.

5. Nandure HP, Puranik P, Giram P, Lone V. Ethosome: A Novel Drug Carrier. International Journal of Pharmaceutical Research and Allied Sciences. 2013;2(3):18-30.

6. Simões SI, Delgado TC, Lopes RM, et al. Developments in the rat adjuvant arthritis model and its use in therapeutic evaluation of novel non-invasive treatment by SOD in Transfersomes. $J$ Control Release. 2005;103(2):419-434.

7. Vinod KR, Kumar MS, Anbazhagan S, et al. Critical issues related to transfersomes - novel vesicular system. Acta Sci Pol Technol Aliment. 2012;11(1):67-82.

8. Romero EL, Morilla MJ. Highly deformable and highly fluid vesicles as potential drug delivery systems: theoretical and practical considerations. Int J Nanomedicine. 2013;8:3171-3186.

9. Cevc G. Transfersomes, liposomes and other lipid suspensions on the skin: permeation enhancement, vesicle penetration, and transdermal drug delivery. Crit Rev Ther Drug Carrier Syst. 1996;13(3-4):257-388.

10. Chen J, Lu WL, Gu W, Lu SS, Chen ZP, Cai BC. Skin permeation behavior of elastic liposomes: role of formulation ingredients. Expert Opin Drug Deliv. 2013;10(6):845-856.

11. ElsayedMM,Cevc G. The vesicle-to-micelle transformation of phospholipidcholate mixed aggregates: a state of the art analysis including membrane curvature effects. Biochim Biophys Acta. 2011;1808(1):140-153.

12. Cevc G, Blume G, Schätzlein A, Gebauer D, Paul A. The skin: a pathway for systemic treatment with patches and lipid-based agent carriers. Adv Drug Deliv Rev. 1996;18(3):349-378.

13. Cevc G, Vierl U, Mazgareanu S. Functional characterisation of novel analgesic product based on self-regulating drug carriers. Int J Pharm. 2008;360(1-2):18-28.

14. Niki E, Traber MG. A history of vitamin E. Ann Nutr Metab. 2012;61(3): 207-212.

15. Niki $E$. Role of vitamin $E$ as a lipid-soluble peroxyl radical scavenger: in vitro and in vivo evidence. Free Radic Biol Med. 2014;66:3-12.

16. Rozman B, Gasperlin M, Tinois-Tessoneaud E, Pirot F, Falson F. Simultaneous absorption of vitamins $\mathrm{C}$ and $\mathrm{E}$ from topical microemulsions using reconstructed human epidermis as a skin model. Eur J Pharm Biopharm. 2009;72(1):69-75.

17. Jovanovic SV, Jankovic I, Josimovic L. Electron-transfer reactions of alkylperoxy radicals. J Am Chem Soc. 1992;114(23):9018-9021.
18. Brigelius-Flohé R, Traber MG. Vitamin E: function and metabolism. FASEB J. 1999;13(10):1145-1155.

19. Dragicevic-Curic N, Gräfe S, Gitter B, Winter S, Fahr A. Surface charged temoporfin-loaded flexible vesicles: in vitro skin penetration studies and stability. Int J Pharm. 2010;384(1-2):100-108.

20. Touitou E, Alkabes M, Dayan N, Eliaz M. Ethosomes: novel vesicular carriers for enhanced skin delivery. Pharm Res. 1997;14:305-306.

21. Cevc G, Vierl U. Nanotechnology and the transdermal route: A state of the art review and critical appraisal. J Control Release. 2010;141(3): 277-299. Available from: http://www.sciencedirect.com/science/ article/pii/S0168365999002229

22. Song CK, Balakrishnan P, Shim CK, Chung SJ, Chong S, Kim DD. A novel vesicular carrier, transethosome, for enhanced skin delivery of voriconazole: characterization and in vitro/in vivo evaluation. Colloids Surf B Biointerfaces. 2012;92:299-304.

23. Bragagni M, Mennini N, Maestrelli F, Cirri M, Mura P. Comparative study of liposomes, transfersomes and ethosomes as carriers for improving topical delivery of celecoxib. Drug Deliv. 2012;19(7):354-361.

24. Lin JY, Selim MA, Shea CR, et al. UV photoprotection by combination topical antioxidants vitamin C and vitamin E. J Am Acad Dermatol. 2003; 48(6):866-874.

25. Paulo MG, Marques HM, Morais JA, Almeida AJ. An isocratic LC method for the simultaneous determination of vitamins A, C, E and beta-carotene. J Pharm Biomed Anal. 1999;21(2):399-406.

26. Chowdhury SR, Maleque M, Shihan MH. Development and Validation of a Simple RP-HPLC Method for Determination of Caffeine in Pharmaceutical Dosage Forms. Asian J Pharm Ana. 2012;2(1):1-4.

27. Nicoli S, Colombo P, Santi P. Release and permeation kinetics of caffeine from bioadhesive transdermal films. AAPS J. 2005;7(1):E218-E223.

28. Cevc G. Rational design of new product candidates: The next generation of highly deformable bilayer vesicles for noninvasive, targeted therapy. $J$ Control Release. 2012;160(2):135-146.

29. FDA. Guidance for Industry, In Vitro Release Testing and In Vivo. Available from: http://www.fda.gov/downloads/Drugs/.../Guidances/ UCM070930.pdf. Accessed April 5, 2014

30. Pharmacopeial Forum (PF) [webpage on the Internet]. Rockville: USP; 2014. Available from: http://www.usp.org/usp-nf/pharmacopeialforum. Accessed April 5, 2014.

31. Domingues MM, Santiago PS, Castanho MA, Santos NC. What can light scattering spectroscopy do for membrane-active peptide studies? J Pept Sci. 2008;14(4):394-400.

32. Ascenso A, Cruz M, Euletério C, et al. Novel tretinoin formulations: a drug-incyclodextrin-in-liposome approach. J Liposome Res. 2013;23(3):211-219.

33. Pham TT, Jaafar-Maalej C, Charcosset C, Fessi H. Liposome and niosome preparation using a membrane contactor for scale-up. Colloids Surf B Biointerfaces. 2012;94:15-21.

34. Lebrette $\mathrm{S}$, Pagnoux C, Abélard P. Stability of aqueous TiO2 suspensions: influence of ethanol. J Colloid Interface Sci. 2004;280(2):400-408.

35. Ahad A, Aqil M, Kohli K, Sultana Y, Mujeeb M. Nano vesicular lipid carriers of angiotensin II receptor blocker: Anti-hypertensive and skin toxicity study in focus. Artif Cells Nanomed Biotechnol. 2015 Feb 24:1-6. [Epub ahead of print].

36. Ascenso A, Salgado A, Euletério C, et al. In vitro and in vivo topical delivery studies of tretinoin-loaded ultradeformable vesicles. Eur J Pharm Biopharm. 2014;88(1):48-55.

37. Goindi S, Dhatt B, Kaur A. Ethosomes-based topical delivery system of antihistaminic drug for treatment of skin allergies. J Microencapsul. 2014;31(7):716-724.

38. Ascenso A, Pinho S, Eleutério C, et al. Lycopene from tomatoes: vesicular nanocarrier formulations for dermal delivery. J Agric Food Chem. 2013;61(30):7284-7293.

39. Scognamiglio I, De Stefano D, Campani V, et al. Nanocarriers for topical administration of resveratrol: a comparative study. Int J Pharm. 2013;440:179-187. 


\section{Supplementary material}

Table SI Physical, chemical, and biologic characteristics of vitamin E and caffeine

\begin{tabular}{|c|c|c|}
\hline Active compounds & $\alpha$-tocopherol or vitamin E & Caffeine \\
\hline Chemical structure & $\mathrm{CH}_{3}$ & O \\
\hline Chemical group & Tocopherols $^{3}$ & Xanthine $^{4}$ \\
\hline IUPAC name & $\begin{array}{l}\text { (2R)-2,5,7,8-Tetramethyl-2-[(4R,8R)-(4,8,I2- } \\
\text { trimethyltridecyl)]-6-chromanol }\end{array}$ & I,3,7-trimethyl-3,7-dihydro- $\mathrm{IH}$--purine-2,6-dione ${ }^{4}$ \\
\hline $\begin{array}{l}\text { Molecular formula } \\
\text { Molar mass }(\mathrm{g} / \mathrm{mol})\end{array}$ & $\begin{array}{l}\mathrm{C}_{29} \mathrm{H}_{50} \mathrm{O}_{2}^{5} \\
430.7 \mathrm{I}^{5}\end{array}$ & $\begin{array}{l}\mathrm{C}_{8} \mathrm{H}_{10} \mathrm{~N}_{4} \mathrm{O}_{2}^{4} \\
194.19^{4}\end{array}$ \\
\hline $\log P$ & $\sim 8.8-10.5^{5}$ & $\sim-0.07 /-0.55^{4}$ \\
\hline Water solubility & Insoluble in water, but water-dispersible ${ }^{5}$ & $\begin{array}{l}\sim 2.16 \mathrm{E}+004 \mathrm{mg} / \mathrm{L} \\
\left(\text { at } 25^{\circ} \mathrm{C}\right)^{4}\end{array}$ \\
\hline Skin distribution & $\begin{array}{l}\text { The distribution rate of vitamin } E \text { along the skin layers is not } \\
\text { similar and Thiele et al }{ }^{6} \text { described an increased quantity of } \\
\text { vitamin } E \text { in the lower SC. }\end{array}$ & $\begin{array}{l}\text { Although caffeine has an efficient penetration in the skin, } \\
\text { the distribution rate of caffeine along the skin layers is } \\
\text { not similar. After application of caffeine emulsion, a tape } \\
\text { stripping test was made and the SC showed an increased } \\
\text { quantity of caffeine comparatively to epidermis and dermis.? }\end{array}$ \\
\hline $\begin{array}{l}\text { Biological activity/ } \\
\text { mechanism of action }\end{array}$ & $\begin{array}{l}\text { Antioxidants, }{ }^{8} \text { being important radical scavengers and } \\
\text { protecting the cells against lipid peroxidation. }{ }^{9} \\
\alpha \text {-tocopherol is the isoform of vitamin E with the most } \\
\text { significant antioxidant activity and with the highest } \\
\text { bioavailability due to a strong affinity to } \alpha \text {-tocopherol } \\
\text { transfer protein and low rate of metabolism. }{ }^{10}\end{array}$ & $\begin{array}{l}\text { Inhibition of phosphodiesterase, antagonist of adenosine } \\
\text { receptors or purinergic PI receptors, and modulation of } \\
\text { calcium handling., }{ }^{2,11,12}\end{array}$ \\
\hline $\begin{array}{l}\text { Therapeutic action on } \\
\text { skin disorders/diseases }\end{array}$ & $\begin{array}{l}\text { Yellow nail syndrome, epidermolysis bullosa, cutaneous } \\
\text { ulcers, wound healing, }{ }^{13} \text { and photoprotection. }{ }^{14} \\
\text { Anticancer activity. }{ }^{15}\end{array}$ & $\begin{array}{l}\text { Psoriasis }{ }^{16} \text { and stimulation of lipolysis in epidermal } \\
\text { adipocytes for the treatment of cellulite. }{ }^{17} \text { Caffeine has also } \\
\text { been studied for the topical treatment of herpes simplex } \\
\text { virus and malignant tumors in mice. }{ }^{12}\end{array}$ \\
\hline
\end{tabular}

Abbreviations: IUPAC, International Union of Pure and Applied Chemistry; SC, stratum corneum.

\section{References}

1. Henning A, Schaefer UF, Neumann D. Potential pitfalls in skin permeation experiments: influence of experimental factors and subsequent data evaluation. Eur J Pharm Biopharm. 2009;72(2): 324-331.

2. Compound Summary for CID 2519: Caffeine [webpage on the Internet]. PubChem Open Bethesda: National Center for Biotechnology Information; 2013. Available from: https://pubchem.ncbi.nlm.nih.gov/ compound/caffeine. Accessed May 20, 2014.

3. Niki E, Traber MG. A history of vitamin E. Ann Nutr Metab. 2012;61(3): 207-212.

4. DrugBank: Caffeine [webapage on the Internet]. DrugBank; 2014. Available from: http://www.drugbank.ca/drugs/DB00201. Accessed May 27, 2014.

5. DrugBank: Vitamin E [webapage on the Internet]. DrugBank; 2014. Available from: http://www.drugbank.ca/drugs/DB00163. Accessed May 27, 2014.

6. Thiele JJ, Traber MG, Packer L. Depletion of human stratum corneum vitamin E: an early and sensitive in vivo marker of UV induced photooxidation. J Invest Dermatol. 1998;110(5):756-761.
7. Potard G, Laugel C, Baillet A, Schaefer H, Marty JP. Quantitative HPLC analysis of sunscreens and caffeine during in vitro percutaneous penetration studies. Int J Pharm. 1999;189:249-260.

8. Niki E. Role of vitamin $\mathrm{E}$ as a lipid-soluble peroxyl radical scavenger: in vitro and in vivo evidence. Free Radic Biol Med. 2014;66:3-12.

9. Rozman B, Gasperlin M, Tinois-Tessoneaud E, Pirot F, Falson F. Simultaneous absorption of vitamins $\mathrm{C}$ and $\mathrm{E}$ from topical microemulsions using reconstructed human epidermis as a skin model. Eur J Pharm Biopharm. 2009;72(1):69-75.

10. Brigelius-Flohé R, Traber MG. Vitamin E: function and metabolism. FASEB J. 1999;13(10):1145-1155.

11. ChemSpider: Caffeine [webpage on the Internet]. London: Royal Society of Chemistry; 2014. Available from: http://www.chemspider. $\mathrm{com} /$ Chemical-Structure. $2424 . \mathrm{html}$ ?rid=565899e4-2f92-4124-81efb317db92ec38. Accessed May 20, 2014.

12. Khazaeli P, Pardakhty A, Shoorabi H. Caffeine-loaded niosomes: characterization and in vitro release studies. Drug Deliv. 2007;14:447-452.

13. Thiele JJ, Ekanayake-Mudiyanselage S. Vitamin E in human skin: organ-specific physiology and considerations for its use in dermatology. Mol Aspects Med. 2007;28(5-6):646-667. 
14. Lin JY, Selim MA, Shea CR, et al. UV photoprotection by combination topical antioxidants vitamin C and vitamin E. J Am Acad Dermatol. 2003; 48(6):866-874.

15. Neuzil J, Dong LF, Ramanathapuram L, et al. Vitamin E analogues as a novel group of mitocans: anti-cancer agents that act by targeting mitochondria. Mol Aspects Med. 2007;28(5-6):607-645.
16. Vali A, Asilian A, Khalesi E, Khoddami L, Shahtalebi M, Mohammady M. Evaluation of the efficacy of topical caffeine in the treatment of psoriasis vulgaris. J Dermatolog Treat. 2005;16(4):234-237.

17. Silva N, Drumond I, Almeida IF, et al. Topical caffeine delivery using biocellulose membranes: a potential innovative system for cellulite treatment. Cellulose. 2014;21(1):665-674.

\section{Publish your work in this journal}

The International Journal of Nanomedicine is an international, peerreviewed journal focusing on the application of nanotechnology in diagnostics, therapeutics, and drug delivery systems throughout the biomedical field. This journal is indexed on PubMed Central, MedLine, CAS, SciSearch $®$, Current Contents $® /$ Clinical Medicine,
Journal Citation Reports/Science Edition, EMBase, Scopus and the Elsevier Bibliographic databases. The manuscript management system is completely online and includes a very quick and fair peer-review system, which is all easy to use. Visit http://www.dovepress.com/ testimonials.php to read real quotes from published authors.

Submit your manuscript here: http://www.dovepress.com/international-journal-of-nanomedicine-journal 